\title{
“CARACTERIZAÇÃO DO MOSTO PARA A PRODUÇÃO DE CERVEJA.”
}

\author{
Célia Regina Bastos dos Santosi'; Giovani Brandão Mafra de Carvalho²; José \\ Francisco Teles de Santana Junior ${ }^{3}$. \\ 1. Bolsista PIBIC/CNPq, Graduando em Engenharia de Alimentos, Universidade Estadual de Feira de Santana, e- \\ mail: celinha_bastos.cr@hotmail.com. \\ 2. Orientador, Departamento de Tecnologia, Universidade Estadual de Feira de Santana, e-mail: \\ brandão.phd@gmail.com. \\ 3. Participante do projeto, Departamento de Tecnologia, Universidade Estadual de Feira de Santana, e-mail: \\ juniorteles95@hotmail.com.
}

PALAVRAS-CHAVE: mosto, malte, cerveja.

\section{INTRODUÇÃO}

A cerveja é considerada uma das bebidas mais consumidas do mundo. É a bebida obtida pela fermentação alcoólica do mosto cervejeiro oriundo de malte de cevada e água potável, por ação da levedura, com adição de lúpulo. (REBELLO,2009).

Para se produzir de cervejas tradicionais, são utilizados mostos de 11 a $12^{\circ}$ Brix, os quais são fermentados para produzir cervejas de 4 a $5 \%(\mathrm{v} / \mathrm{v})$ de etanol. O mosto pode ser preparado puro malte, ou utilizando complementos ou adjuntos, afim de baratear o processo, sendo capaz de proporcionar material fermentescível adicional ao mosto, sendo o malte de cevada um ingrediente muito importante para a elaboração de cervejas, servindo como fonte de carboidratos, proteínas, minerais. Segundo MAPA (2009), o mosto cervejeiro é a solução, em água potável, de carboidratos, proteínas, glicídios e sais minerais, resultantes da degradação dos componentes da matéria prima, que compõem o mosto.

Esse trabalho busca estudar a obtenção e caracterização do mosto cervejeiro puro malte, avaliando sua qualidade que poderá servir posteriormente para trabalhos futuros, como elaboração de cervejas utilizando adjuntos, visto que, as cervejas artesanais têm, nos últimos anos, crescido de forma elevada afim de reduzir o custo de operação durante a produção, aumentando utilidade do tanque de fermentação e maturação.

\section{MATERIAL E MÉTODOS OU METODOLOGIA (ou equivalente)}

As matérias primas foram obtidas em lojas online especializadas em insumos cervejeiros, o preparo do mosto foi realizado conforme metodologia desenvolvida por CARVALHO, 2009.

O mosto cervejeiro foi caracterizado quanto aos seguintes parâmetros: o teor de umidade, extrato, sacarose, acidez (livre, lactônica e total), açúcares redutores (AR) e açúcares redutores totais (ART) (COPERSUCAR, 2001), pH (determinado diretamente pelo pHmetro digital); sólido solúveis totais (SST), determinado por leitura direta em refratômetro digital (Reichert, model AR200), carboidratos totais, através do método de ANTRONA (TREVELYAN, HARRISON, 1952), e açúcares redutores segundo Nelson (1944). Conforme (IAL, 1985), foi determinado acidez total titulável (ATT) pelo método titulométrico com solução padronizada de $\mathrm{NaOH} 0,1 \mathrm{~N}$; cinzas, através da calcinação das amostras a $550^{\circ} \mathrm{C}$; umidade, pelo método da estufa sob pressão reduzida a $70^{\circ} \mathrm{C}$ até peso constante; lipídeos, através da extração realizada pelo método Soxhlet; e proteínas, pelo método de Kjeldahl.

RESULTADOS E/OU DISCUSSÃO (ou Análise e discussão dos resultados) 
O processo de preparação do mosto cervejeiro foi realizado de acordo com o método demonstrado por CARVALHO, 2009. Para a produção do mosto puro malte, fez-se necessário realizar as seguintes etapas demonstrada no fluxograma abaixo:

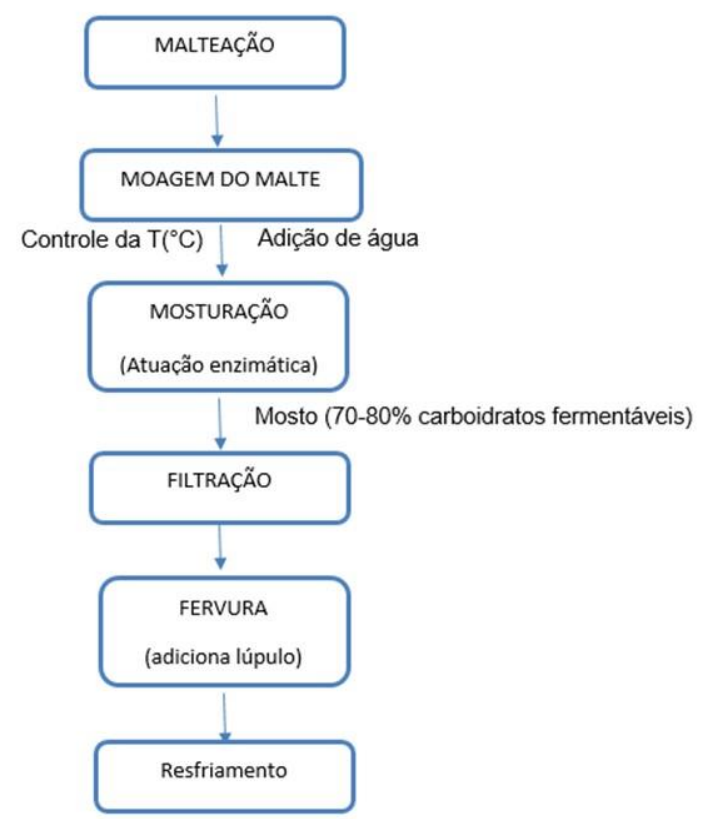

Fonte: $\mathrm{O}$ autor

Figura 1 - Fluxograma do processo de mosturação.

O mosto cervejeiro puro malte foi analisado físico-quimicamente e seus resultados são apresentados na tabela 2 .

\begin{tabular}{c|c} 
PARAMÊTRO & RESULTADO \\
\hline Umidade (\%) & $91,23 \pm 0,103$ \\
Sólidos Solúveis ( $\left.{ }^{\circ} \mathbf{B r i x}\right)$ & $11,00 \pm 0,018$ \\
Proteína Bruta (g/100g) & $1,83 \pm 0,086$ \\
Lipídios (g/100g) & $1,66 \pm 0,105$ \\
Acidez Total (meq/Kg) & $1,45 \pm 0,015$ \\
Açucares Redutores (g/100g) & $15,10 \pm 0,020$ \\
Açucares Totais (g/100g) & $1,14 \pm 0,216$ \\
pH (adimensional) & $5,32 \pm 0,011$ \\
Cinzas (\%) & $0,15 \pm 0,012$ \\
Amido & NEGATIVO
\end{tabular}

Tabela 2: Caracterização físico-química do mosto cervejeiro.

O mosto puro malte produzido apresentou $11^{\circ}$ Brix e essa quantidade de sólidos solúveis encontrada, aponta o máximo de açúcares que foi capaz de extrair, estando abaixo valor demonstrado por Brasil (2009), que afirma que as cervejas fabricadas com mostos a 12 ${ }^{\circ}$ Brix são classificadas como comuns pela legislação brasileira. Para aumentar extrato ( ${ }^{\circ}$ Brix), uma das alternativas seria aumentar o tempo de fervura ou a quantidade de malte para a produção do mosto, que iria fornecer mais açucares presentes a serem extraídos durante a maturação. Ao aumentar o tempo de fervura, o mosto ficaria mais concentrado, 
devido a uma maior quantidade de água ser evaporada, tendo por consequência, um menor rendimento do mosto.

$\mathrm{O}$ valor do $\mathrm{pH}$ do mosto puro malte foi de 5,3, não havendo a necessidade de corrigilo, estando na faixa ideal $(5,3$ - 5,5) demonstrada por Kunze (2006), e segundo Briggs (2004), os valores inferiores a pH 5,0 podem prejudicar na clarificação da cerveja.

O teor de proteína bruta do mosto correspondente a $1,83 \%$, foi determinado através de uma conversão do teor total de nitrogênio em proteína por um fator de 6,25. Meilgaard (2002) mostra que para esta quantidade de sólidos solúveis presentes no mosto, o valor médio de proteínas é de $0,43 \%$, sedo compreendido numa faixa de 0,30\%-0,60\%. Assim, verifica-se que o valor de proteína encontrado experimentalmente está acima da faixa determinada pelo autor.

O resultado obtido para a acidez total foi de $1,45 \%$, sendo esta resultante dos ácidos orgânicos, capaz de influência na cor, sabor, aroma, assim como, na qualidade da cerveja. Os teores de umidade encontrados foram de 91,23\%, valor próximo ao encontrado por BRUNELLI \& VENTURINI FILHO (2013) para uma cerveja comum puro malte, com mosto de $11^{\circ}$ Brix. Para essa mesma concentração de extrato também demonstrou através de seus estudos, um teor de lipídio de $0,17 \%$. O resultado obtido para o teor de lipídeos foi de $1,66 \%$, sendo, portanto, uma quantidade alta quando comparado aos dados obtidos experimentalmente por esses autores.

A determinação do teor de cinzas, fornece uma indicação da riqueza dos elementos minerais presente no mosto, obtendo um valor de $0,15 \%$.

Os teores encontrados para os açucares redutores e açucares totais foram de $15,10 \%$ e $1,14 \%$ respectivamente. A quantidade de açúcares presentes na cerveja é proveniente do extrato primitivo e influenciará no seu valor calórico.

$\mathrm{O}$ teor de amido negativo de amido demonstra que este foi convertido em açucares menores capazes de fermentar, atribuindo boa qualidade ao mosto, isto porque, caso haja existência de alguma fração de amido, poderá provocar alguns problemas o processo fermentativo e que vá a afetar no aspecto sensorial na cerveja, a turbidez é uma delas.

\section{CONSIDERAÇÕES FINAIS}

Através do presente trabalho foi possível caracterizar o mosto cervejeiro puro malte, sendo viável e importante para conhecer as propriedades físico-químicas do mesmo. O mosto produzido apresentou $11^{\circ}$ Brix, com quantidade de sólidos solúveis abaixo do valor que a legislação brasileira determina (12 ${ }^{\circ}$ Brix) para ser classificada como cerveja comum. $\mathrm{O}$ pH do mostro se encontrou dentro da faixa ideal enquanto o teor proteico mostrou-se acima da faixa compreendida. Ao comparar o teor de umidade com outros autores que realizaram o mesmo estudo para uma mesma quantidade de extrato, percebeu-se a proximidade entre os valores, sendo, portanto, influenciada pela quantidade de sólidos solúveis presentes.

\section{REFERÊNCIAS}

BRASIL. Ministério da Agricultura e do Abastecimento. Decreto $\mathrm{n}^{\circ}$ 6.871, de 04. Regulamenta da Lei ${ }^{\circ} 8.918$ de 14 de julho de 1994, que dispõe sobre a padronização, a classificação, o registro, a inspeção e a fiscalização da produção e do comércio de bebidas. Diário Oficial da União, Brasília, 04 de junho de 2009.

BRIGGS. D. E.; BOULTON, C. A.; BROOKES, P. A.; STEVENS, R. Brewing Science and Practice, Cambridge: CRC Press, 2004.

CARVALHO, G.B.M.de. Obtenção de Cerveja usando Banana como Adjunto e Aromatizante. 2009. 163f. Tese (Doutorado em Biotecnologia Industrial) - Escola de Engenharia de Lorena, Universidade de São Paulo, 2009. 
BRUNELLI, Luciana Trevisan; VENTURINI FILHO, Waldemar Gastoni. ANÁLISE ENERGÉTICA DE CERVEJA ELABORADA COM MEL. Energia na Agricultura, v. 28, n. 2, p. 122-128, 2013.

COPERSUCAR S.A. Métodos analíticos. In: COPERSUCAR S.A. Manual de Controle Químico da Fabricação de Açúcar. Piracicaba: Centro de Tecnologia Copersucar, 2001. cap. 4, p. 1-51.

INSTITUTO ADOLFO LUTZ - IAL. Normas analíticas do Instituto Adolfo Lutz: métodos químicos e físicos para análise de alimentos. 3. ed. São Paulo: O Instituto, 1985.

KUNZE, W. La cerveza terminada. In: Berlín: VLB Berlin, 2006. cap. 7, p. 826-885.

. Tecnología para cerveceros y malteros.

MEILGAARD, M. Composición del Mosto. In: KLIMOVITZ, R. El cervecero en la práctica. 3.ed. Minnesota: Master Brewers Association of Americas, 2002.

MAPA- Ministério da_Agricultura, Pecuária e Abastecimento. DECRETO N ${ }^{\circ} 2.314$, DE 4 DE ${ }^{-}$SETEMBRO DE 1997. Disponível em: $<$ http://www.agricultura.gov.br/assuntos/vigilancia-agropecuaria/ivegetal/bebidas-

arquivos/decreto-no-2-314-de-4-de-setembro-de-1997.doc/view>. Acesso em: 2 ago.2018.

NELSON, N.A. 1944. A photometric adaptation of Somogyi method for the determination of glucose. Journal of Biological Chemistry 135: 375.

TREVELYAN, W.E.; HARRISON, T.S. Dosagem de glicídeos totais pelo método de antrona. J.Biochem., v. 50, p. 292, 1952. 